Conference Paper

\title{
Numerical design and optimisation of a novel heatsink using ANSYS steady-state thermal analysis
}

Mueller, A., Buennagel, C., Monir, S., Sharp, A., Vagapov, Y. and Anuchin, A

This is a paper presented at the 27th Int. Workshop on Electric Drives, Moscow, Russia, 2730 Jan. 2020.

Copyright of the author(s). Reproduced here with their permission and the permission of the conference organisers.

\section{Recommended citation:}

Mueller, A., Buennagel, C., Monir, S., Sharp, A., Vagapov, Y. and Anuchin, A (2020) 'Numerical design and optimisation of a novel heatsink using ANSYS steady-state thermal analysis'. In: Proc. 27th Int. Workshop on Electric Drives, Moscow, Russia, 27-30 Jan. 2020, pp. 1-5. doi: 10.1109/IWED48848.2020.9069568 


\section{Numerical Design and Optimisation of a Novel Heatsink using ANSYS Steady-State Thermal Analysis}

\author{
Andre Mueller \\ Glyndwr University \\ Wrexham, UK \\ Andrew Sharp \\ Glyndwr University \\ Wrexham, UK
}

\author{
Christian Buennagel \\ Glyndwr University \\ Wrexham, UK \\ Yuriy Vagapov \\ Glyndwr University \\ Wrexham, UK
}

\author{
Shafiul Monir \\ Glyndwr University \\ Wrexham, UK \\ Alecksey Anuchin \\ Moscow Power Engineering Institute \\ Moscow, Russia
}

\begin{abstract}
This paper presents a numerical study of thermal performance on heatsink configurations for power electronic devices. The analysis was based on numerical modelling using the CFD software ANSYS 19.1 Steady-State Thermal. The heatsink geometrical features are investigated and compared with each other. The effects of material selection, total surface area, temperature uniformity and maximum surface temperature are assessed. The increase of surface area, implementation of geometrical features, and high thermal conductive material was found to reduce the maximum surface temperature and improve overall thermal dissipation capacity. With a constrained base $(50 \mathrm{~mm} \times 50 \mathrm{~mm} \times 5 \mathrm{~mm})$, the novel designs incorporating secondary branches lead to best thermal performance, achieving up to $50 \%$ improvement in thermal efficiency. It was concluded that the implementation of nature inspired geometrical features and material configuration, studied in this work exhibits significant benefits for applications in heatsink for electronic devices.
\end{abstract}

Keywords-ANSYS, thermal analysis, cooling, heatsink, nature inspiration

\section{INTRODUCTION}

The power density of modern power electronic devices is dramatically increased over the last decade. This increase demands implementation of effective cooling systems for power electronic applications to provide safe and reliable operation [1],[2]. Heatsinks with flat based geometries are very popular solution for cooling of various electronic devices mainly due to low manufacturing cost and high operational reliability [3]. Thermal performance of heatsink depends on a number of parameters such as geometry, material, operating conditions and working fluids, etc. Therefore, the optimisation of such parameters is crucial for an effective heatsink design. The classification of heatsinks has been prescribed by Kandlikar and Grande [4] based on the dimensional size of the channel available. A range of dimensions have been assigned, $10 \mu \mathrm{m}-200 \mu \mathrm{m}$ for microchannels, $200 \mu \mathrm{m}-3 \mathrm{~mm}$ for mini-channels, and $>3 \mathrm{~mm}$ for conventional channels. Tukerman and Pease [5] proposed and demonstrated the effectiveness of mini channels for electronic devices' cooling by presenting efficient heat dissipation with a heat flow of $790 \mathrm{~W} / \mathrm{m}^{2}$ with a nominal temperature rise of $71^{\circ} \mathrm{C}$ on the base surface. The introduction of ribs, grooves, and fins [6]-[10] on micro channel heatsink has been found to be more effective in

This work was supported by the Russian Ministry of Education and Science grant (Project № 8.8313.2017/BCh). terms of improvement of cooling performance. This has also been approved in a series of experimental investigations conducted and presented by KhoshvaghtAliabadi et al. [11]-[13]. Ahmed [14] experimentally investigated the effect of implementation of ribs on a flat plate heatsink. The efficiency of cooling has been analysed under varying of parameters such as position, alignment, size and number of ribs. An improvement of $55 \%$ for thermal performance was found due to the installation of ribs on the surface of flat plate heatsink [14]. The heat transfer performance of a heatsink with the channels has been found to be dependent on the geometrical shape of the channels. Study of rectangular, trapezoidal, circular and triangular channels concluded that rectangular mini-channel heatsink was found to be the best compared to triangular and trapezoidal mini/micro channel heatsink [15]-[19]. The introduction of secondary branches on wavy micro-channels was preformed experimentally and numerically by Chiam et al. [20]. It has been found that the heat transfer performance is increased due to addition of secondary branches. This study is primarily focused on a novel heatsink which geometrical shape is inspired by nature and has wavy branches.

\section{Numerical Setup ANd VALidation}

\section{A. Numerical Setup}

Simplified 3D models of heatsink are developed using a combined mesh not exceeding 200,000 cells. The base of the flat based heatsink is constrained to the following dimensions W50 $\mathrm{mm} \times \mathrm{D} 50 \mathrm{~mm} \times \mathrm{H} 5 \mathrm{~mm}$ and total height fixed at $55 \mathrm{~mm}$. Heat flow $(Q)$ was assigned to the under surface of the heatsink and convection $(h)$ employed on all other surfaces. The ambient (air) temperature $\left(T_{\infty}\right)$ was maintained at $24.85^{\circ} \mathrm{C}$ and thermal conductivity $(k)$ of material was employed, respectively. All simulations are conducted using the CFD software ANSYS 19.1.

\section{B. Validation}

The numerical validation was conducted for a given case study, which incorporates a power electronic device with a thermal output of $130 \mathrm{~W}$. In order to avoid damage to the power electronic semiconductor, the maximum surface temperature must not exceed the value of $99.85^{\circ} \mathrm{C}$. Temperature at the heatsink base $\left(B_{T}\right)$ can be calculated theoretically using a simplified heatsink model (HS-1) and correlated with results obtained from numerical modelling. The dimensions of HS-1 are as follows; HS-1 base: width 
$\left(w_{b}\right) 50 \mathrm{~mm} \times$ length $\left(L_{b}\right) 50 \mathrm{~mm} \times$ thickness $\left(t_{b}\right) 5 \mathrm{~mm}$, HS-1 fins: width $(w) 50 \mathrm{~mm} \times$ length $(L) 50 \mathrm{~mm} \times$ thickness $(t)$ $2 \mathrm{~mm}$, and number of fins $N=10$. The following boundary conditions are prescribed; heat flow $(Q)$ of $130 \mathrm{~W}$ is employed to under surface of HS-1, thermal conductivity (k) for aluminium of $250 \mathrm{~W} / \mathrm{m} \cdot \mathrm{K}$ assigned for global material, convection coefficient $(h)$ of $39.8 \mathrm{~W} / \mathrm{m}^{2} \mathrm{~K}$ employed to all other surfaces, and $24.85^{\circ} \mathrm{C}$ for the ambient temperature $\left(T_{\infty}\right)$. The following equations are used to determine $B_{T}$ for validation.

The area of heatsink bottom surface $A_{b}$ is calculated as

$$
A_{b}=W_{b} \times L_{b}
$$

where $W_{b}$ is the width of heatsink base, and $L_{b}$ is the length. The top area of the heatsink fin can be found the following formula

$$
A_{c}=w \times t
$$

where $w$ is fin width, and $t$ is fin thickness. The fin side area can be found as

$$
A_{p}=t \times L
$$

where $L$ is fin length. The real length of fin $L_{f}$ is

$$
L_{f}=L+\frac{t}{2}
$$

The fin perimeter can be found as

$$
P=2 \times w+2 \times t
$$

The free area between fins is

$$
A_{d}=A_{b}-N \times A_{c}
$$

where $N$ is the number of blades, $A_{b}$ and $A_{c}$ are obtained from (1) and (2), respectively. The complete area of each fin can be obtained as

$$
A_{f}=2 \times w \times L_{f}
$$

where $L_{f}$ is the fin length obtained from (4). The total area of the fins including the base $A_{t}$ is

$$
A_{t}=N \times A_{f}+A_{d}
$$

The thermal resistance of the HS-1 base can be determined as

$$
R_{H-\text { Base }}=\frac{t_{b}}{k \times A_{b}}
$$

where $k$ is the thermal conductivity of the heatsink material, and $t_{b}$ is the heatsink base thickness. The fin efficiency is

$$
\eta_{f}=\frac{\tanh \left(n \times L_{f}\right)}{n \times L_{f}}
$$

where $L_{f}$ is the real length of fin determined using (4), $n$ can be derived from (11).

$$
n=\left(\frac{h \times P}{k \times A_{c}}\right)^{\frac{1}{2}}
$$

The total efficiency of the heatsink can now be determined using (12).

$$
\eta_{0}=1-\frac{N \times A_{f}}{A_{t} \times \eta_{f}}
$$

The thermal resistance from the heatsink base to fins can be calculated using (13).

$$
R_{t, 0}=\frac{1}{h \times A_{t} \times \eta_{0}}
$$

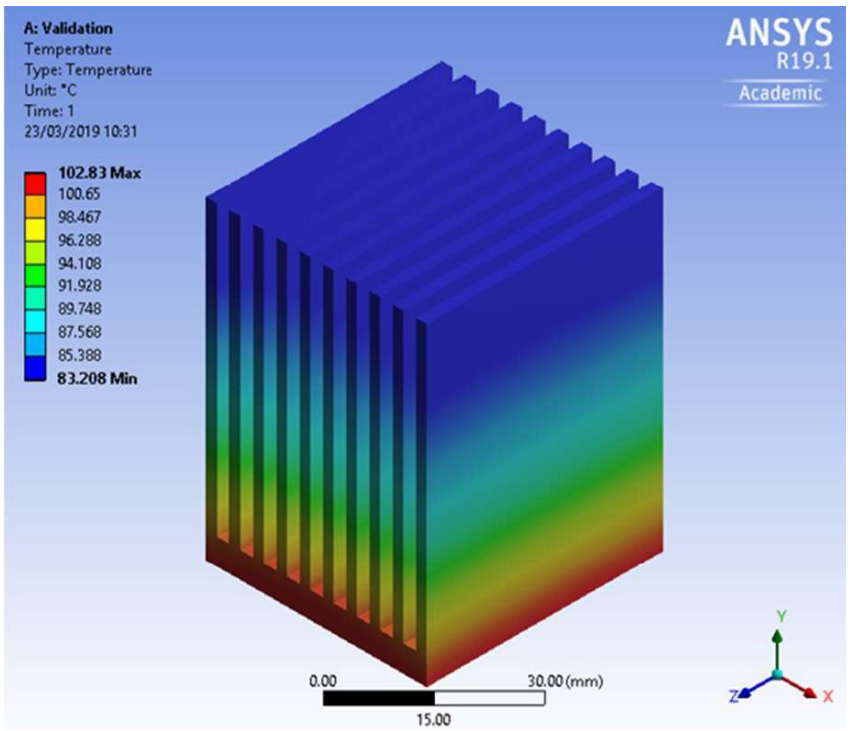

Fig. 1. Contours of total temperature for validation case study HS-1, presenting maximum surface temperature of $102.83^{\circ} \mathrm{C}$ on the underside of the HS-1.

where $h$ is the convection coefficient. The temperature at the base of the heatsink can now be calculated from (14).

$$
B_{T}=Q \times\left(R_{H-\text { Base }}+R_{t, 0}\right)+T_{\infty}
$$

where $Q$ is the heat flow, and $T_{\infty}$ is the ambient temperature.

The theoretical $B_{T}$ was calculated as $99.75^{\circ} \mathrm{C}$, which is within the desired limits for this validation case study. Simulation results under same conditions presented $102.83^{\circ} \mathrm{C}$ observing temperature difference $\left(\Delta_{T}\right)$ of $3.08^{\circ} \mathrm{C}$.

There are many factors that can be attributed for $\Delta_{T}$ such as simplification of numerical model or mesh characteristics in ANSYS Meshing. Therefore, adoption of $\Delta_{T}$ as a numerical error tolerance, is considered within this study.

\section{Material Selection}

In order to present influences of material properties have on heatsink thermal performance, HS-1 model was further analysed with different material properties that can be beneficial for the application of the novel heatsink for power electronic devices. The five selected materials are presented in Table I and compared regarding their thermal properties $k$.

The comparison of maximum surface temperature is presented above in Fig. 2. It can be observed that diamond achieved the lowest surface temperature of $89^{\circ} \mathrm{C}$ compared to stainless steel, having the highest surface temperature of $189^{\circ} \mathrm{C}$. This is due to thermal properties, where $k$ for

Table I Thermal Conductivity $(k)$ For Material Selection for Novel Heatsink, for Temperature Range of $25^{\circ} \mathrm{C}-225^{\circ} \mathrm{C}$.

\begin{tabular}{|c|c|c|c|}
\hline Material & $\mathbf{2 5}^{\circ} \mathbf{C}$ & $\mathbf{1 2 5}^{\circ} \mathbf{C}$ & $\mathbf{2 2 5}^{\circ} \mathbf{C}$ \\
\hline Aluminium & 205 & 215 & 250 \\
\hline Copper & 401 & 400 & 398 \\
\hline Iron & 80 & 68 & 60 \\
\hline Stainless steel & 16 & 17 & 19 \\
\hline Diamond & 2000 & 2000 & 2000 \\
\hline
\end{tabular}




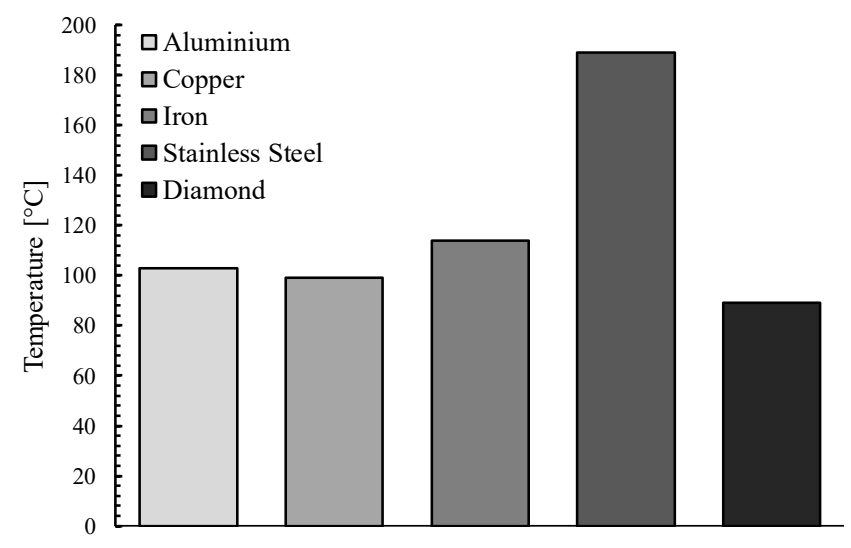

Fig. 2. Numerical results for maximum surface temperature for HS-1, employing different global material for HS-1.

diamond is greater than stainless steel. Aluminium, iron, and copper are well suited for heatsink material considering cost and functionality. However, for the purpose if this study diamond and stainless steel will be used for best- and worst-case scenarios, respectively.

\section{Novel Heatsink Designs}

Five different numerical models have been developed for novel heatsink designs. All models have a fixed base and height mentioned previously, and parametric studies have been conducted, varying geometrical features in order to attain the best design for a novel heatsink. HS-1 is the benchmark model for numerical comparison. HS-2 (Fig. 4a) consists of tubular pillars with implemented cylindrical voids, HS-3 (Fig. 4b) consists of rotational fins to maximise surface area, HS-4 and HS-5 (Fig. 4c and

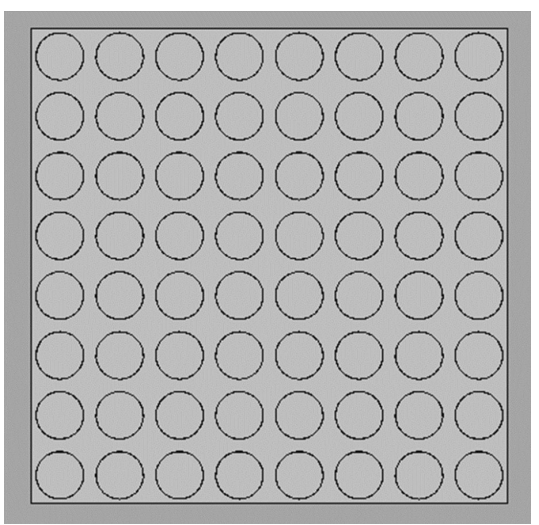

a)

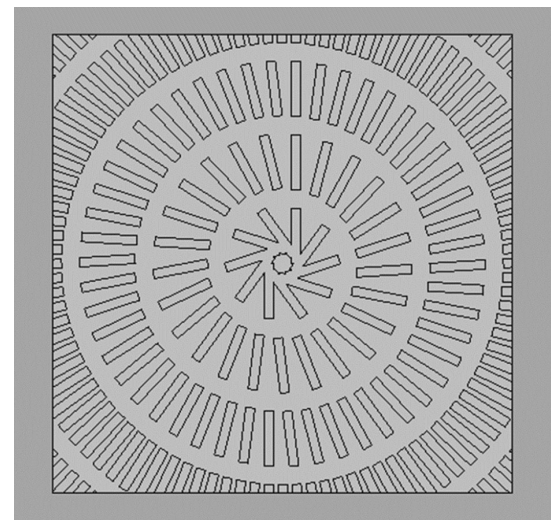

b)

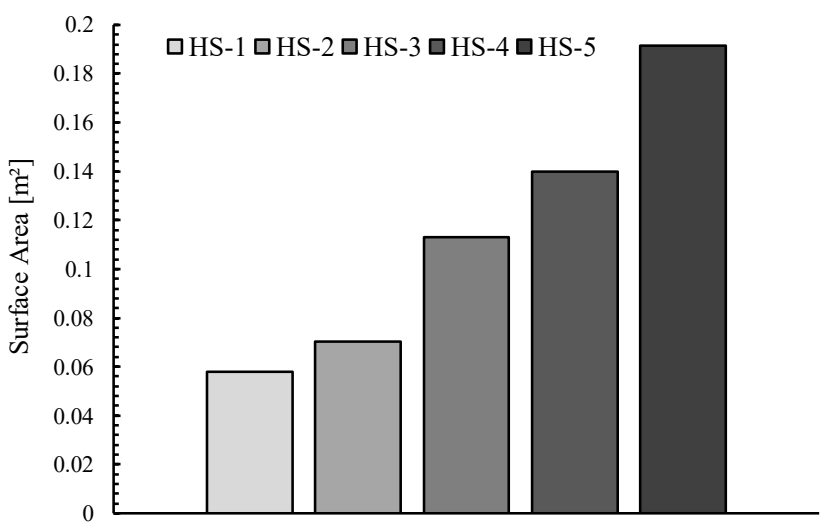

Fig. 3. Total surface area for novel HS designs, obtained directly from ANSYS software.

Fig. 4d, respectively) employs multiple branches, inspired by nature to further increase total surface area. However, such designs may have fabrication constraints, where cost and manufacturing feasibility need to be considered. A possible adaptive manufacturing method FFF (Fused Filament Fabrication) under the use of FMP (Filament Metal Printing) can be considered [21].

The total surface area of each model is presented in Fig. 3. It can be observed that introduction of multiple branches for HS-4 and HS-5 results in an increase of global surface area.

\section{Results AND Discussion}

Performance analysis are conducted on all heatsink designs numerically. All novel heatsink designs are

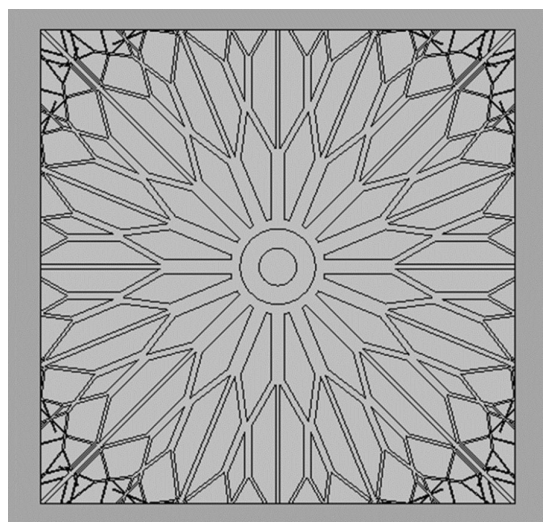

c)

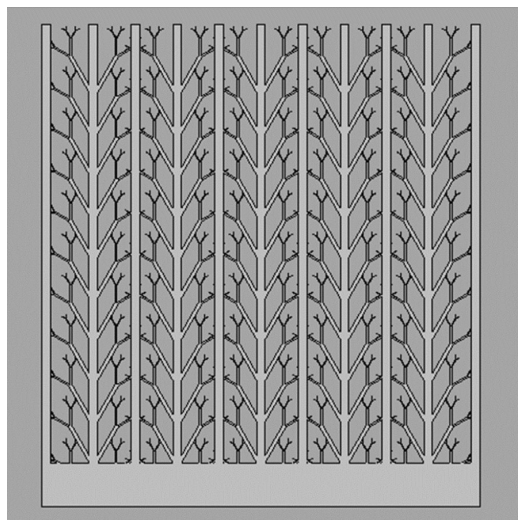

d)

Fig. 4. Schematic representation of novel heatsink designs, (a) top view of HS-2 cylindrical pillars, (b) top view of HS-3 rotational fins, (c) top view of HS-4 double branch-1, and (d) side view of HS-5 double branch-2. 


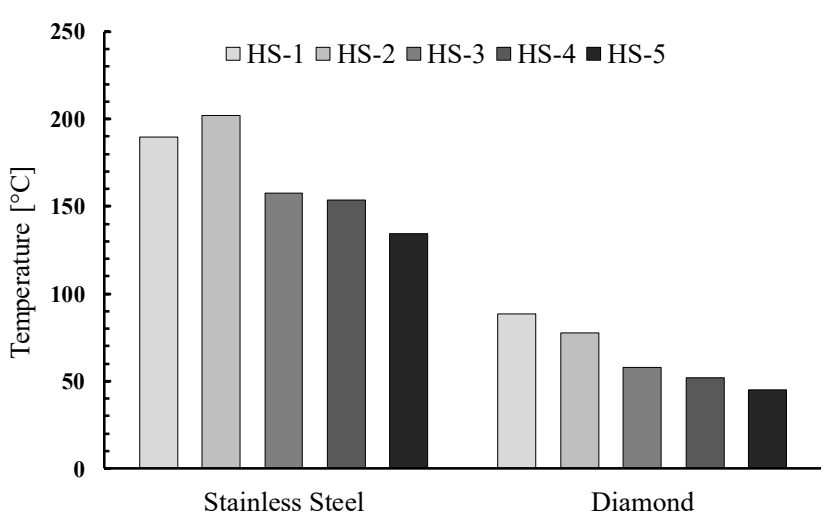

Fig. 5. Total temperature for novel heatsink designs, compared with selected materials, stainless steel and diamond.

benchmarked against the HS-1 model to evaluate their merits. The numerical simulations are performed using ASNSYS Steady-State Thermal, with $Q$ and $h$ set as 130W and $39.8 \mathrm{~W} / \mathrm{m}^{2} \mathrm{~K}$ respectively to determine the thermal dependencies of individual heatsink.

\section{A. Temperature}

Fig. 5. presents total surface temperature for all heatsink designs; it can be observed that total temperature is reduced with increase of global surface area. This applies to all heatsink designs when employing diamond as primary material, were HS-5 (Fig. 5) achieved lowest temperature of $44.85^{\circ} \mathrm{C}$

The adoption of branches for HS-4 and HS-5 enhances dissipation capacity allowing uniform temperature distribution, correlating well with findings from Chiam et al. [20] who found heat transfer performance increased due to the addition of secondary branches. However, in the case of HS-2 when employing stainless steel as primary material, resulted in a temperature increase of $202.08^{\circ} \mathrm{C}$ (Fig. 8) which is unacceptable for the safe operation of the power electronic device and will likely brings an unrecovered damage of the semiconductor structure. This increase in temperature is due to the cylindrical voids on the pillar, which decreased overall material mass.

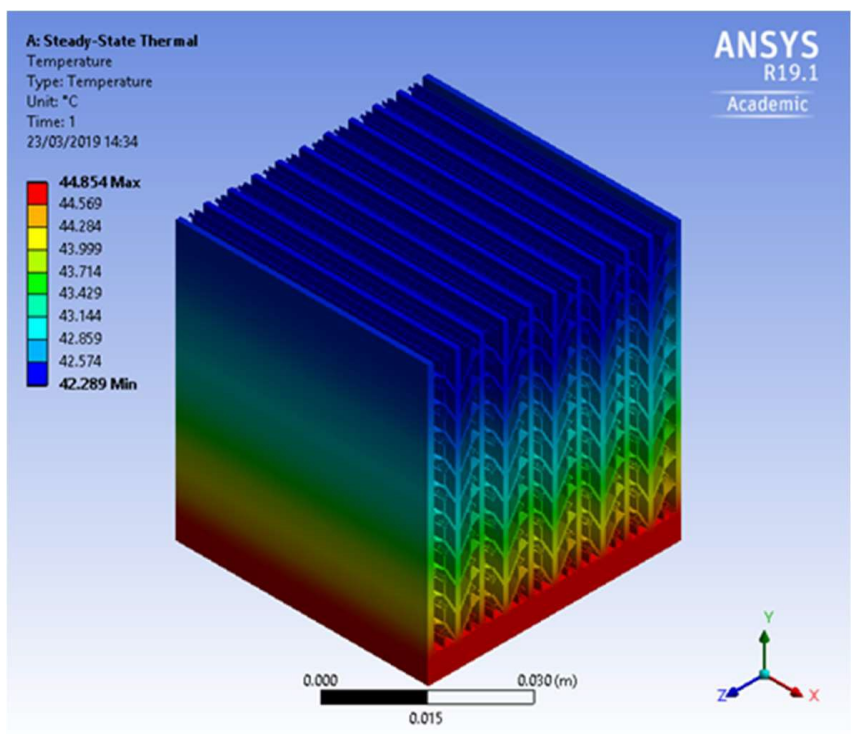

Fig. 6. Contours of total temperature for HS-5, presenting maximum surface temperature of $44.85^{\circ} \mathrm{C}$ on the underside of base plate.

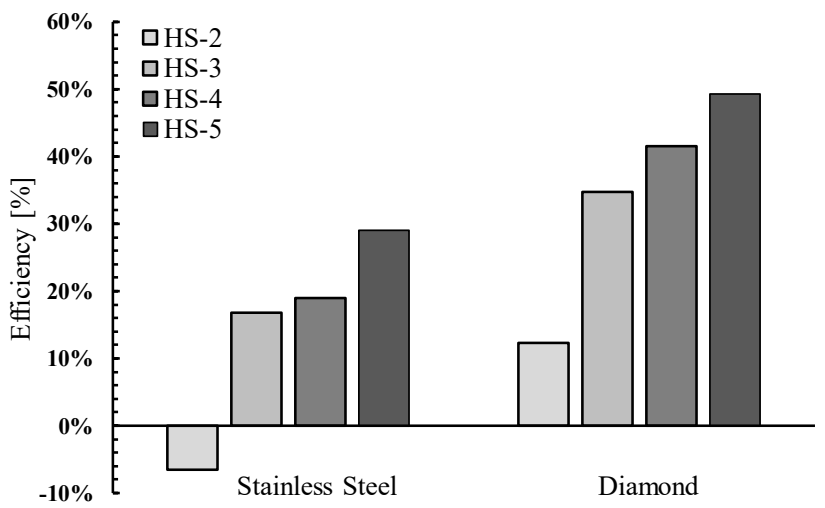

Fig. 7. Thermal efficiency for heatsink designs, compared with selected materials, stainless steel and diamond.

Such voids have a negative effect on the dissipation capacity, resulting in temperature increase located at the base of heatsink. However, HS-2 performs better when employing diamond as primary material, which provides further evidence that material properties have a direct influence on the overall thermal performance.

\section{B. Thermal Efficiency}

The thermal efficiency can provide further insight into thermal performance of heatsink. The efficiency can be calculated using (15).

$$
\eta_{T}=\frac{\Delta T}{T}=\frac{T_{H S-1}-T_{H S-n}}{T_{H S-1}}
$$

Fig. 7. shows thermal efficiency of $49.37 \%$ achieved for HS-5, this can be explained by the implementation of secondary branches sandwiched between flat side plates. The side plates provide greater surface area which are connected to the micro branches allowing excellent thermal dissipation capacity.

HS-5 also achieved highest thermal efficiency of $29 \%$ for stainless steel, further correlating that geometrical feature have direct influence on thermal performance on heatsink. The adaption of geometrical features can have positive influences as seen for HS-5, however HS-2 observed a decrease in efficiency of $6.5 \%$ when compared to HS-1 benchmark model.

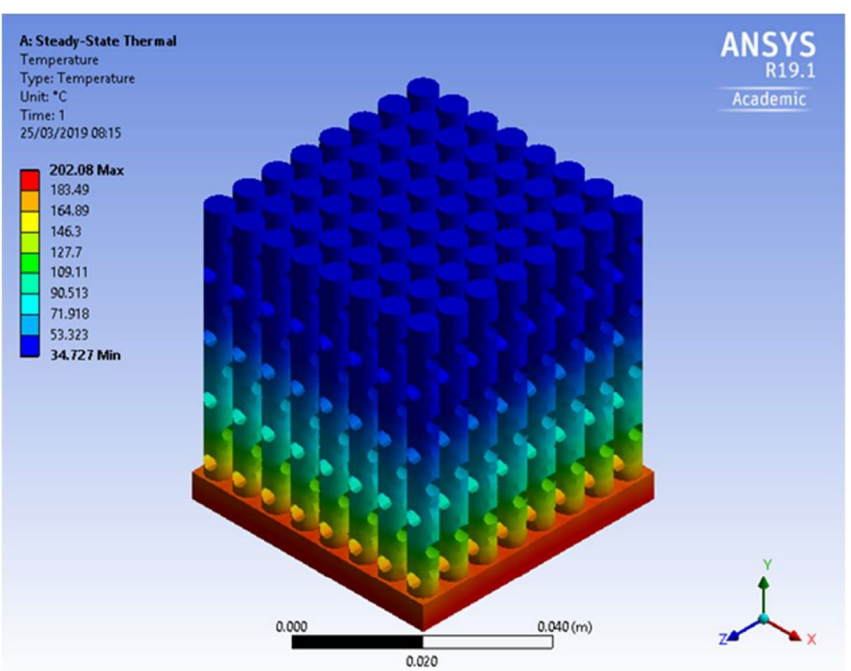

Fig. 8. Contours of total temperature for HS-2, presenting maximum surface temperature of $202.08^{\circ} \mathrm{C}$ on the underside of base plate. 


\section{CONCLUSION}

To evaluate thermal efficiency of the proposed heatsink several numerical simulations were performed. A validation study was based on a power semiconductor device generating a thermal output of $130 \mathrm{~W}$. After the successful validation of the theoretical results with numerical results, the comprehensive analysis of temperature gradients in the heatsinks was conducted. The conclusions based on the obtained results are:

- A significant correlation between the global surface area and thermal performance are observed. Furthermore, thermal conductivity of the primary material used for heatsink plays a key role for thermal efficiency.

- The thermal efficiency of up to $50 \%$ can be achieved for HS-5. This is due to configuration of secondary branches sandwiched between flat side plates increasing the thermal dissipation capacity. This gives room for using less expensive materials while utilising improved geometrical heatsink design.

- Due to the geometrical complexity of the novel heatsink designs inspired by nature, additive manufacturing could be considered as a suitable method. One process using Fused Filament Fabrication (FFF) can be utilised for Filament Metal Printing (FMP) [21],[22] for production of novel heatsinks.

\section{REFERENCES}

[1] H. Tang, Y. Tang, Z. Wan, J. Li, W. Yuan, L. Lu, Y. Li, and K. Tang, "Review of applications and developments of ultra-thin micro heat pipes for electronic cooling," Applied Energy, vol. 223, no. 1, pp. 383-400, Aug. 2018.

[2] J.-S. Ko, J.-H. Huh, and J.-C. Kim, "Improvement of energy efficiency and control performance of cooling system fan applied to Industry 4.0 data center," Electronics, vol. 8, no. 5, article 582, May 2019.

[3] M.B. Dogruoz, M. Urdaneta, and A. Ortega, "Experiments and modeling of the hydraulic resistance and heat transfer of in-line square pin fin heat sinks with top by-pass flow," International Journal of Heat and Mass Transfer, vol. 48, nos. 23-24, pp. 50585071, Nov. 2005

[4] S.G. Kandlikar, and W.J. Grande, "Evolution of microchannel flow passages-Thermohydraulic performance and fabrication technology," Heat Transfer Engineering, vol. 24, no. 1, pp. 3-17, 2003.

[5] D.B. Tuckerman, and R.F.W. Pease, "High-performance heat sinking for VLSI," IEEE Electron Device Letters, vol. 2, no. 5, pp. 126-129, May 1981.

[6] G. Xie, S. Zheng, W. Zhang, and B. Sunden, "A numerical study of flow structure and heat transfer in a square channel with ribs combined downstream half-size or same-size ribs," Applied Thermal Engineering, vol. 61, Ino. 2, pp. 289-300, Nov. 2013.

[7] R. Roth, G. Lenk, K. Cobry, and P. Woias, "Heat transfer in freestanding microchannels with in-line and staggered pin fin structures with clearance," International Journal of Heat and Mass Transfer, vol. 67, pp. 1-15, Dec. 2013.
[8] T. Adachi, and H. Uehara, "Correlation between heat transfer and pressure drop in channels with periodically grooved parts," International Journal of Heat and Mass Transfer, vol. 44, no. 22, pp. 4333-4343, Nov. 2001.

[9] C.-H. Huang, and Y.-H. Chen, "An optimal design problem in determining non-uniform fin heights and widths for an impingement heat sink module," Applied Thermal Engineering, vol. 63, no. 2, pp. 481-494, Feb. 2014.

[10] J. Dong, L. Su, Q. Chen, and W. Xu, "Experimental study on thermal -hydraulic performance of a wavy fin-and-flat tube aluminum heat exchanger," Applied Thermal Engineering, vol. 51, nos. 1-2, pp. 3239, Mar. 2013.

[11] M. Khoshvaght-Aliabadi, M. Sahamiyan, M. Hesampour, and O. Sartipzadeh, "Experimental study on cooling performance of sinusoidal-wavy minichannel heat sink," Applied Thermal Engineering, vol. 92, pp. 50-61, Jan. 2016.

[12] M. Khoshvaght-Aliabadi, and M. Sahamiyan, "Performance of nanofluid flow in corrugated minichannels heat sink (CMCHS)," Energy Conversion and Management, vol. 108, pp. 297-308, Jan. 2016.

[13] M. Khoshvaght-Aliabadi, and F. Nozan, "Water cooled corrugated minichannel heat sink for electronic devices: Effect of corrugation shape," International Communications in Heat and Mass Transfer, vol. 76, pp. 188-196, Aug. 2016.

[14] H.E. Ahmed, "Optimization of thermal design of ribbed flat-plate fin heat sink," Applied Thermal Engineering, vol. 102, pp. 1422-1432, June 2016.

[15] P.-S. Lee, S.V. Garimella, and D. Liu, "Investigation of heat transfer in rectangular microchannels," International Journal of Heat and Mass Transfer, vol. 48, no. 9, pp. 1688-1704, April 2005.

[16] H.A. Mohammed, P. Gunnasegaran, and N.H. Shuaib, "The impact of various nanofluid types on triangular microchannels heat sink cooling performance," International Communications in Heat and Mass Transfer, vol. 38, no. 6, pp. 767-773, July 2011.

[17] Y. Chen, C. Zhang, M. Shi, and J. Wu, "Three-dimensional numerical simulation of heat and fluid flow in noncircular microchannel heat sinks," International Communications in Heat and Mass Transfer, vol. 36, no. 9, pp. 917-920, Nov. 2009.

[18] W. Owhaib, and B. Palm, "Experimental investigation of singlephase convective heat transfer in circular microchannels," Experimental Thermal and Fluid Science, vol. 28, nos. 2-3, pp. 105110, Jan. 2004.

[19] P. Gunnasegaran, H.A. Mohammed, N.H. Shuaib, and R. Saidur, "The effect of geometrical parameters on heat transfer characteristics of microchannels heat sink with different shapes," International Communications in Heat and Mass Transfer, vol. 37, no. 8, pp. 1078 -1086 , Oct. 2010.

[20] Z.L. Chiam, P.S. Lee, P.K. Singh, and N. Mou, "Investigation of fluid flow and heat transfer in wavy micro-channels with alternating secondary branches," International Journal of Heat and Mass Transfer, vol. 101, pp. 1316-1330, Oct. 2016.

[21] P.F. Flowers, C. Reyes, S. Ye, M.J. Kim, and B.J. Wiley, “3D printing electronic components and circuits with conductive thermoplastic filament," Additive Manufacturing, vol. 18, pp. 156163, Dec. 2017.

[22] BASF Technical Data Sheet Ultrafuse 316L [Online]. Available: https://www.innofil3d.com/ultrafuse_316_1_sds_gen_eu_en_v1-1/ 